\title{
Hydrotalcite-Derived Mixed Oxides for the Synthesis of a Key Vitamin A Intermediate Reducing Waste
}

\author{
Journal Article \\ Author(s): \\ Coumans, Ferdy J.A.G.; Mitchell, Sharon; Schütz, Jan; Medlock, Jonathan; Pérez-Ramírez, Javier \\ Publication date: \\ 2018-11-30 \\ Permanent link: \\ https://doi.org/10.3929/ethz-b-000305924 \\ Rights / license: \\ In Copyright - Non-Commercial Use Permitted \\ Originally published in: \\ ACS Omega 3(11), https://doi.org/10.1021/acsomega.8b02234
}




\section{Hydrotalcite-Derived Mixed Oxides for the Synthesis of a Key Vitamin A Intermediate Reducing Waste}

Ferdy J. A. G. Coumans, ${ }^{\dagger}$ Sharon Mitchell,,$^{* \dagger}$ Jan Schütz,,$^{\ddagger}$ Jonathan Medlock, ${ }^{\ddagger}$ and Javier Pérez-Ramírez ${ }^{*} \dagger \odot$

${ }^{\dagger}$ Institute for Chemical and Bioengineering, Department of Chemistry and Applied Biosciences, ETH Zurich, Vladimir-Prelog-Weg 1, 8093 Zurich, Switzerland

${ }^{\ddagger}$ DSM Nutritional Products Ltd., P.O. Box 2676, 4002 Basel, Switzerland

Supporting Information

ABSTRACT: The synthesis of hydroxenin monoacetate, a key intermediate in the manufacture of vitamin $\mathrm{A}$, relies on the undesirable use of stoichiometric amounts of organic bases such as pyridine. Although the final product (vitamin A acetate) can be produced from hydroxenin diacetate, using the monoacetylated intermediate improves the overall process yield. Aiming to identify more efficient, environmentally benign alternatives, this work first studies the homogeneous acetylation reaction using pyridine. The addition of the base is found to enhance the rate of hydroxenin monoacetate formation, confirming its catalytic role, but also yields

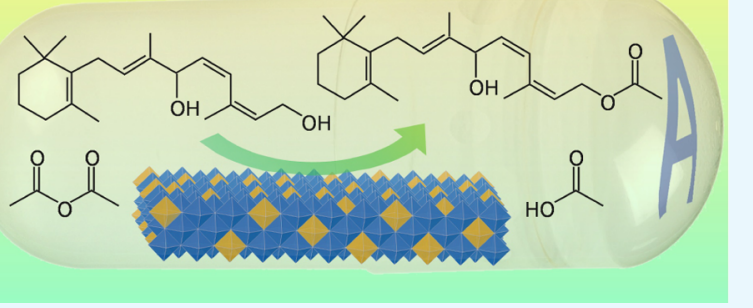
non-negligible amounts of hydroxenin diacetate. On the basis of these insights, $\mathrm{Mg}$ - and Al-containing hydrotalcites are explored because of their broad scope as base catalysts and the ability to finely tune their properties. The reaction kinetics are greatly enhanced via controlled thermal activation, forming high surface area mixed metal oxides displaying Lewis basic sites. In contrast, a Brønsted basic material synthesized by the reconstruction of a mixed oxide performs similarly to the as-synthesized hydrotalcite. Variation of the $\mathrm{Mg} / \mathrm{Al}$ ratio from 1 to 3 has no significant impact, but activity losses are observed at higher values because of a reduced number of basic sites. After optimizing the reaction conditions, hydroxenin monoacetate yields $>60 \%$ are obtained in five consecutive cycles without the need for any intermediate treatment. The findings confirm the potential of hydrotalcite-derived materials as highly selective catalysts for the production of vitamins with reduced levels of organic waste.

\section{INTRODUCTION}

Vitamins were recognized as essential micronutrients at the start of the 20th century. ${ }^{1}$ In line with continued economic development, an increased demand for nutritional products is forecast in the coming years. ${ }^{2}$ Current production routes still generally use stoichiometric amounts of soluble reagents. However, the increasing pressures on resources and the environment are driving a search for more sustainable alternatives, including the transition from batch to continuous and from stoichiometric to catalytic processes, and the substitution of soluble reagents with solid alternatives. ${ }^{3-5}$ Despite dedicated efforts to implement heterogeneous catalysts, their application in vitamin production is still limited because of the challenges in attaining highly selective conversions of complex compounds. ${ }^{5-8}$ Furthermore, companies aim to develop unique synthetic routes to generate intellectual property. ${ }^{9}$ For example, up to five different processes, each with distinct intermediates, have been developed for the production of vitamin A, which is important for many biological functions including growth, immunity, vision, and reproduction. ${ }^{1,10}$

Hoffmann-La Roche first commercialized a process for the production of the more stable vitamin A acetate derivative in the 1950 s. ${ }^{1,10}$ As seen in Scheme 1, hydroxenin is obtained via several carbon elongations starting from $\beta$-ionone. Even though the final product can be synthesized from the diacetylated intermediate, higher yields of the dehydration/ elimination step can be obtained when using the pure monoacetate derivative. ${ }^{11,12}$ The first patented procedure for the acetylation of hydroxenin (Scheme 1, boxed reaction) required large amounts of pyridine and used acetyl chloride or acetic anhydride as acetylating agents. ${ }^{13,14}$ Although equimolar amounts of base are required, the specific chemical function of pyridine, either as a proton scavenger or as a nucleophilic catalyst, has never been elucidated. To improve the process efficiency and reduce waste formation, a continuous enzymecatalyzed acetylation was pursued. ${ }^{11,12}$ However, despite achieving very high levels of conversion, it has only been demonstrated on a pilot scale, the addition of a base and antioxidant was still necessary. Furthermore, enzyme activity deteriorated substantially without the aid of a $\mathrm{Na}_{4}$ EDTA precolumn. On the basis of the reaction type, hydrotalcites and their derived mixed metal oxides could be suitable replacements for pyridine, as these materials are promising base

Received: August 31, 2018

Accepted: October 26, 2018

Published: November 12, 2018 
Scheme 1. Synthesis of Vitamin A Acetate Developed by Hoffmann-La Roche Starting from $\beta$-Ionone ${ }^{1,10 a}$

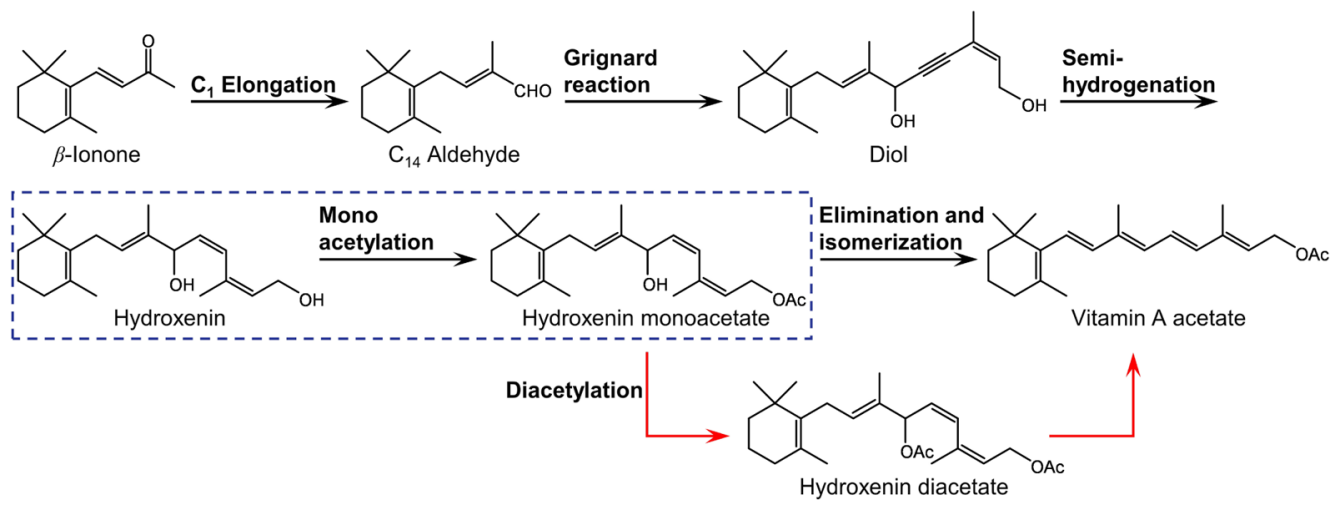

${ }^{a}$ Boxed step indicates the reaction targeted in this study. The formation of the diacetate derivative may lead to a significant reduction in the final product yield.

Scheme 2. Schematic Representation of the Structural Evolution of Hydrotalcites upon Thermal Activation (Red Arrows), Highlighting the Dehydration and Subsequent Phase Transformations at Elevated Temperatures ${ }^{a}$

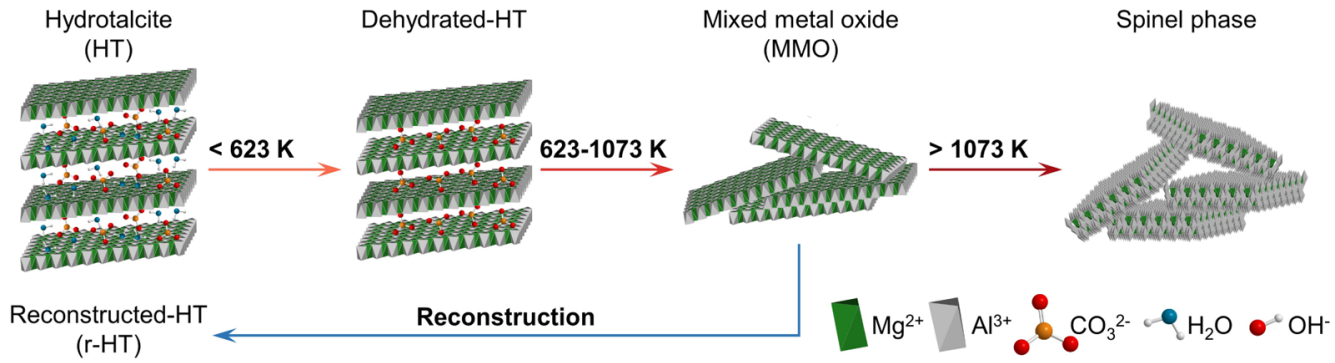

${ }^{a}$ Controlled reconstruction of the mixed metal oxide by treatment in water (blue arrow) offers the possibility to prepare a carbonate-free, hydroxylcontaining analogue.

catalysts in various chemical transformations. ${ }^{15-28}$ Several works have reported their application in transesterification reactions, ${ }^{22-28}$ which are closely related to the targeted acetylation of hydroxenin. These works have identified the importance of optimizing the surface area and number of basic sites of the hydrotalcite via thermal activation. Furthermore, the type of active center was reported to have a critical impact; the introduction of Brønsted basicity through the reconstruction of thermally decomposed hydrotalcites with water vapor resulted in decreased conversion in the transesterification of lipids. $^{25}$ Little attention has been given toward selective transformations of complex molecules, such as in the synthesis of vitamin A.

In this study, the use of solid bases is demonstrated for the first time in the selective acetylation of an industrially relevant vitamin A intermediate. To gain an insight into the reaction mechanism, the acetylation of hydroxenin in the presence of pyridine is first investigated. On the basis of these results, synthesis-property-performance relations are assessed over hydrotalcite-based materials through variation of the activation conditions and metal content (Scheme 2). After maximizing the monoacetate yield through tuning of the reaction parameters, the stability of the best performing material is evaluated. Hydroxenin monoacetate yields $>60 \%$ are evidenced during five consecutive batch tests without intermediate treatment of the catalyst.

\section{RESULTS AND DISCUSSION}

2.1. Chemical Function of the Homogenous Base. To design a solid replacement, it was first necessary to investigate the acetylation of hydroxenin in the presence of pyridine-one of the most active organic bases currently applied. ${ }^{29}$ This was approached by monitoring the conversion and product yield during batch experiments following a representative lab-scale procedure (Figure 1a). The solvent, reactant, base, and products could be clearly identified by high-performance liquid chromatography (HPLC), as illustrated for representative catalytic tests in Figure S1. A conversion of above $80 \%$ is evidenced in the presence of pyridine, which is over 10 times higher than that observed in the blank reaction in the absence of any base ( $8 \%)$. Comparison of the product yields reveals non-negligible formation of the diacetylated product (ca. 20\%). To understand this result, the acetylation of hydroxenin monoacetate was also studied. Once again, higher conversion (ca. 4 times) toward hydroxenin diacetate $(>25 \%$ yield) results in the presence of pyridine (Figure $1 \mathrm{~b}$ ).

The observations are consistent with pyridine having a dual function both as a base and as a nucleophilic catalyst, converting acetic anhydride $\mathbf{1}$ into a more active acetylating agent 2. ${ }^{30}$ This species is able to react with the secondary alcohol producing more appreciable amounts of diacetate (Scheme 3). Although pyridine is applied in close to stoichiometric quantities, the highly enhanced kinetics in the presence of this base and the fact that it is not consumed in the reaction suggest that the acetylation is base catalyzed. Indeed, estimation of an apparent turnover number with respect to 
$i=$ amonoacetate $\square$ diacetate $\square$ hydroxenin
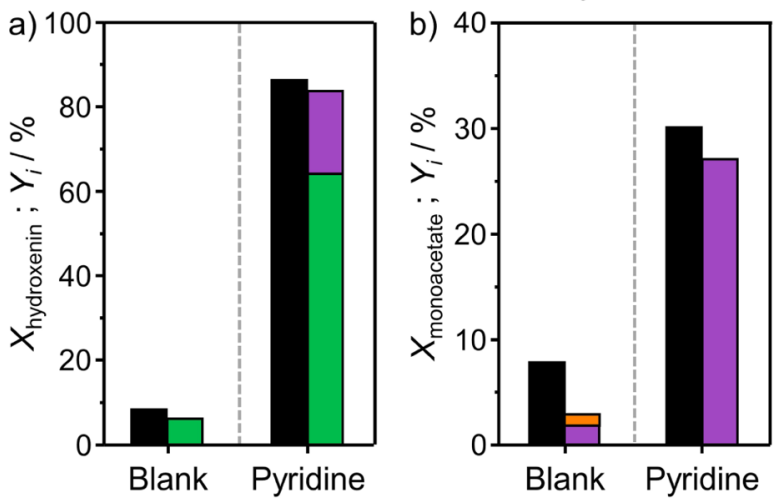

Figure 1. Impact of pyridine on the acetylation of (a) hydroxenin or (b) hydroxenin monoacetate using acetic anhydride as an acetylating agent: conversion (black bars) and product yields (colored bars). Conditions: $T=303 \mathrm{~K}, t=4 \mathrm{~h}, V=10 \mathrm{~cm}^{3}, n_{\text {hydroxenin }}$ or $n_{\text {hydroxenin monoacetate }}=3.3 \mathrm{mmol}, n_{\text {acetic anhydride }}=4.3 \mathrm{mmol}$, and $n_{\text {pyridine }}=$ $2.6 \mathrm{mmol}$ (where applied).

pyridine yields a value greater than 1 , even when considering the expected uncatalyzed conversion based on the blank experiment. Additionally, the formation of intramolecular hydrogen bonds in the hydroxenin molecule (3) could also have a stabilizing effect, reducing the activity in the blank reactions. ${ }^{31}$ No acetylation was observed when acetic acid was used, as this neutralizes pyridine, supporting this hypothesis. The intention to replace this homogeneous base with a solid catalyst could also improve the acetylation selectivity.

2.2. Design of a Heterogeneous Base Catalyst. To develop a heterogeneous alternative to the use of organic bases in this reaction, we turned to hydrotalcites, that is, layered double hydroxides with the formula $\left[\mathrm{Mg}_{n}{ }^{2+} \mathrm{Al}_{m}{ }^{3+}(\mathrm{OH})_{2(n+m)}\right]^{m+}\left[\mathrm{CO}_{3}{ }^{2-}\right]_{m / 2} \cdot x \mathrm{H}_{2} \mathrm{O}$. The wide synthetic tunability of these compounds enables assessment of the impact of different variables (e.g., the type, number, and strength of basic sites) on the activity (Scheme 2). ${ }^{32-34}$ To identify key parameters for the conversion of hydroxenin, a hydrotalcite with a nominal $\mathrm{Mg} / \mathrm{Al}$ ratio of 3 (denoted HT3) and containing carbonate anions was initially synthesized (Table S1). X-ray diffraction (XRD) patterns reveal the characteristic reflections of a rhombohedral (3R) layered double hydroxide structure (Figure 2a) and the porous properties determined by nitrogen adsorption agree with previous studies (Figure $2 \mathrm{~b}$ and Table S2). ${ }^{35,36}$

Thermal activation of HT3 at temperatures in the range from 673 to $1273 \mathrm{~K}$ resulted in the formation of the mixed metal oxides (MMOx-y) as evidenced by the relatively broad reflections centered at 43 and $62^{\circ} 2 \theta$ (Figure 2a). As expected, reflections corresponding to the $\mathrm{MgAl}_{2} \mathrm{O}_{4}$ spinel phase appear a)
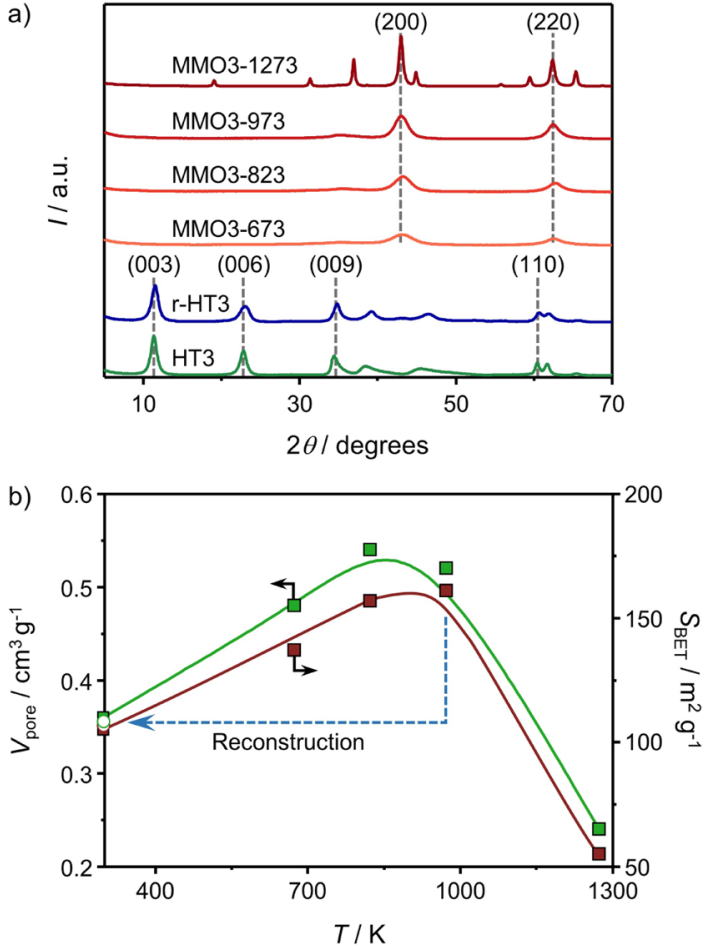

Figure 2. (a) XRD patterns and (b) porous properties of HT3, the mixed metal oxides obtained upon its thermal activation at different temperatures, and the hydrotalcite prepared by reconstruction of MMO3-973 (see arrow). Phase assignment was achieved with respect to reference patterns reported in the crystallographic open database: hydrotalcite (9009272), $\mathrm{MgO}$ (100053), and $\mathrm{MgAl}_{2} \mathrm{O}_{4}$ (9005807).

in the diffractogram of the sample heated to $1273 \mathrm{~K}$, indicating the loss of the mixed oxide structure. ${ }^{37}$ The evolution of porous properties upon thermal activation is consistent with previous observations (Figure $2 \mathrm{~b}$ ). The surface area reaches a maximum value of $161 \mathrm{~m}^{2} \mathrm{~g}^{-1}$ at $973 \mathrm{~K}$, subsequently showing a marked drop upon formation of the spinel phase $\left(55 \mathrm{~m}^{2} \mathrm{~g}^{-1}\right)$. An advantage of these materials for the conversion of bulky substrates is their mesoporous character (the average pore diameter in the MMO3-y samples varied between 11 and 14 $\mathrm{nm}$, Table S1), which ensures a large accessible surface area. The ${ }^{27} \mathrm{Al}$ magic angle spinning nuclear magnetic resonance (MAS NMR) spectra confirm the transition toward the mixed oxide, as more tetrahedral $\left(T_{d}\right) \mathrm{Al}$ species are formed with an increasing temperature (Figure S2) ${ }^{37}$ However, splitting of the signal at $71 \mathrm{ppm}$ is indicative of some phase segregation of aluminum in the MMO3-1273 sample. ${ }^{38,39}$ The controlled reconstruction of the hydrotalcite-derived mixed metal oxides in decarbonized water permits the formation of the carbonatefree hydrotalcite, meixnerite, which contains hydroxide anions

Scheme 3. Proposed Mechanism for the Mono- and Diacetylation of Hydroxenin with Acetic Anhydride and Pyridine

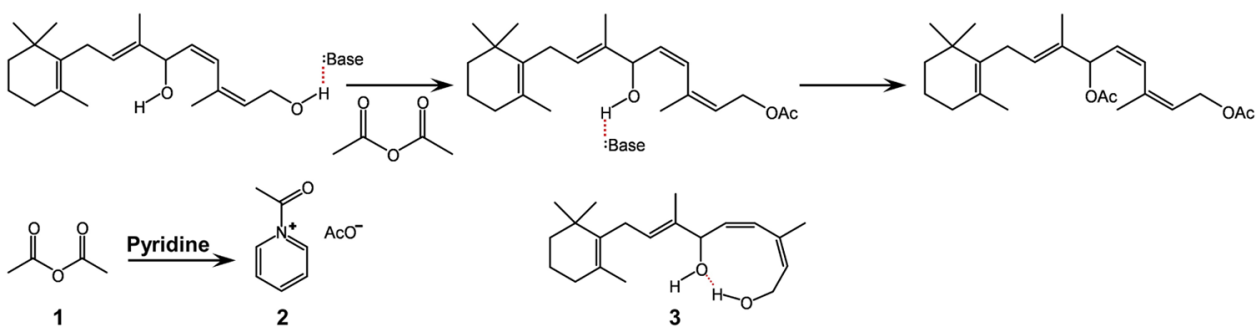


originating Brønsted basic sites (Scheme 2). ${ }^{40}$ The successful reconstruction of MMO3-973 leading to r-HT3 was evidenced by XRD, and the material exhibits similar porous properties to the as-synthesized HT3 (Figure 2). Elemental analysis indicated a carbon content $(0.7$ wt \%) much lower than that expected for a fully carbonate-exchanged hydrotalcite of this composition (i.e., 1.52 wt \%, see Table S1). The complete elimination of carbon from these materials is very difficult to achieve because of the rapid adsorption of $\mathrm{CO}_{2}$ upon exposure to air, but the value is sufficiently low to consider that the majority of charge-balancing anions have been replaced by hydroxide groups and that residual ethanol is unlikely to play a significant role. ${ }^{41}$

The performance of hydrotalcites and derived materials was evaluated under equivalent conditions as applied for pyridine (Figure 3a). The results confirm a noticeably increased activity over HT3 compared to the blank test (Figure 1). ${ }^{35,42}$ Thermal activation of this hydrotalcite leads to enhanced catalytic
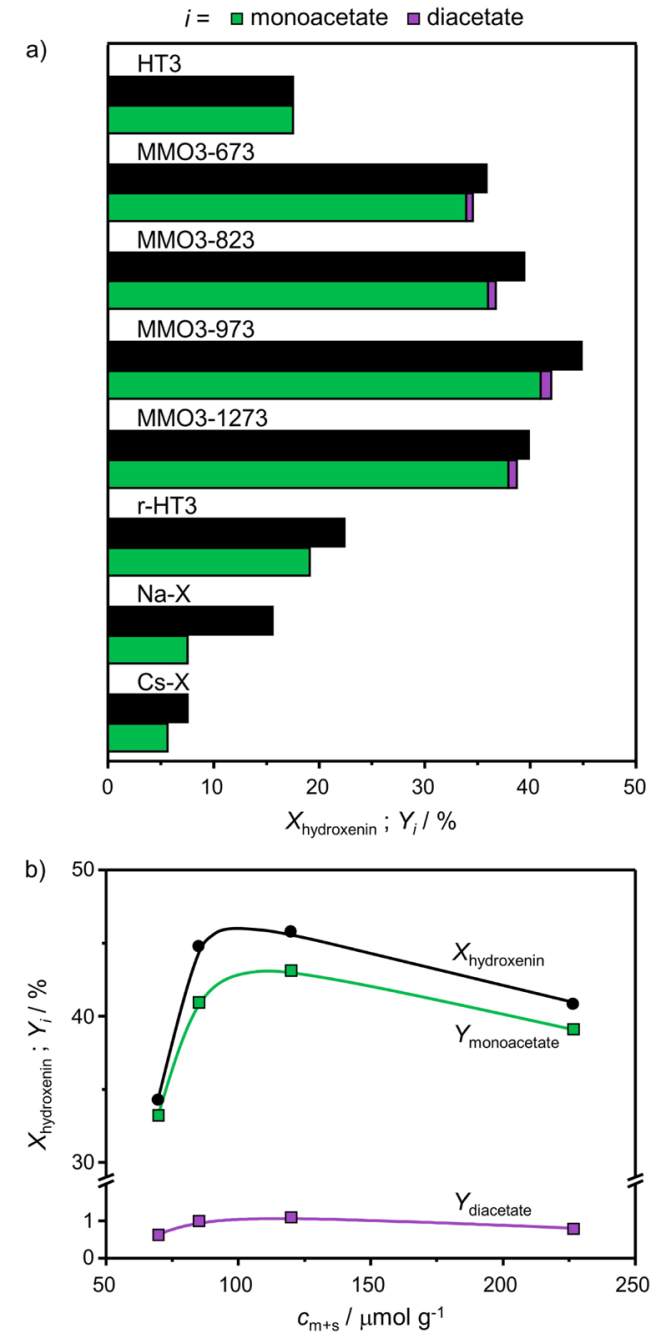

Figure 3. (a) Hydroxenin conversion (black bars) and product yields (colored bars) in the presence of HT3 and the catalysts derived by its thermal activation and reconstruction. The performance of the basic zeolite catalysts is shown for comparison. (b) Performance as a function of the combined amount of medium and strong basic sites in the mixed metal oxides of varying $\mathrm{Mg} / \mathrm{Al}$ ratio activated at $973 \mathrm{~K}$. Conditions: $T=303 \mathrm{~K}, w_{\text {cat }}=250 \mathrm{mg}, n_{\text {hydroxenin }}=3.3 \mathrm{mmol}$, $n_{\text {acetic anhydride }}=4.3 \mathrm{mmol}, V=10 \mathrm{~cm}^{3}, t=6 \mathrm{~h}$. properties; the sample treated at $973 \mathrm{~K}$ reaching a conversion of $45 \%$ and a monoacetate yield of $41 \%$. This suggests that the increased surface area of these materials, and the expected presence of higher concentrations of Lewis basic sites, ${ }^{46}$ is beneficial for the performance in the reaction. In comparison, r-HT3 displayed a similar activity to the as-synthesized hydrotalcite with a monoacetate yield of $19 \%$, indicating that the presence of Lewis basic sites is more influential in this reaction. In all cases, the diacetate yield remained below $2 \%$, illustrating the highly selective nature of these materials in acetylation reactions. It is worth noting that prolonged exposure of the mixed metal oxides to ambient conditions resulted in a gradual decrease of the activity. For example, the hydroxenin conversion over MMO3-973 dropped by approximately $40 \%$ (from 45 to $26 \%$ ) if exposed to ambient conditions for 1 week prior to testing. The activity loss could be completely reversed upon reactivation of the material at the original temperature, suggesting that the adsorption of carbon dioxide and water from air could lead to the partial reconstruction of the surface, reducing the number of accessible basic sites.

Additional hydrotalcite materials were prepared with nominal $\mathrm{Mg} / \mathrm{Al}$ ratios of 1,2 , and 4 . The actual metal ratios approached these values (Table S1), and the surface area increased simultaneously with the aluminum content in the range from 56 to $167 \mathrm{~cm}^{2} \mathrm{~g}^{-1}$ (Table S3). Typical layered double hydroxide reflections are observed in the XRD patterns (Figure S3) and move to higher $2 \theta$ values upon increasing the $\mathrm{Al}$ content, which is in agreement with the literature. ${ }^{43}$ The octahedral $\left(O_{h}\right)$ symmetry of aluminum in the as-synthesized hydrotalcites was confirmed by ${ }^{27} \mathrm{Al}$ MAS NMR (Figure S4).$^{44,45}$ As expected, peak broadening indicates the hindered incorporation of $\mathrm{Al}$ into the brucite-like layers at a $\mathrm{Mg} / \mathrm{Al}$ ratio of 1 . Thermal activation of the as-synthesized hydrotalcites at $973 \mathrm{~K}$ yielded similar materials to the MMO3-973 sample. Enhanced surface areas are evidenced with increasing metal ratio in good agreement with other reported literature (Table S3). ${ }^{46}$ The crystal size is slightly increased for higher $\mathrm{Mg} / \mathrm{Al}$ ratios (4.6 nm in MMO4-973), which agrees with the lower amount of aluminum. This material also has the highest reflection intensity in the XRD patterns (Figure S5). ${ }^{20}$ Consistent with the greater structural heterogeneity of HT1, MMO1-973 displays the largest peak broadening. This is also observed by ${ }^{27} \mathrm{Al}$ MAS NMR (Figure S6).

No appreciable influence of the metal ratio was evidenced from the performance, with all as-synthesized hydrotalcites achieving similar activity (Figure S7). Basicity assessment is widely approached by the temperature-programmed desorption (TPD) of $\mathrm{CO}_{2}$. Unfortunately, most of the thermally activated materials still contain small amounts of $\mathrm{CO}_{2}$ adsorbed on the surface, which can perturb the desorption profile making it challenging to deconvolute. Thus, although as expected thermogravimetric analysis (TGA) of the decomposition of the hydrotalcite indicates that the removal of volatile species is essentially complete after calcination at approximately $773 \mathrm{~K}$ (Figure S8), ${ }^{47}$ blank experiments, without introducing $\mathrm{CO}_{2}$, revealed that degassing at $973 \mathrm{~K}$ is needed to fully remove any adsorbed species. For this reason, and in view of the superior performance, our analysis focused on the catalysts activated at $973 \mathrm{~K}$. Examination of the $\mathrm{CO}_{2}$ desorption profiles shows that the peaks in the range of 473$673 \mathrm{~K}$ become more pronounced with increasing aluminum content (Figure S9). This region is often attributed to the 

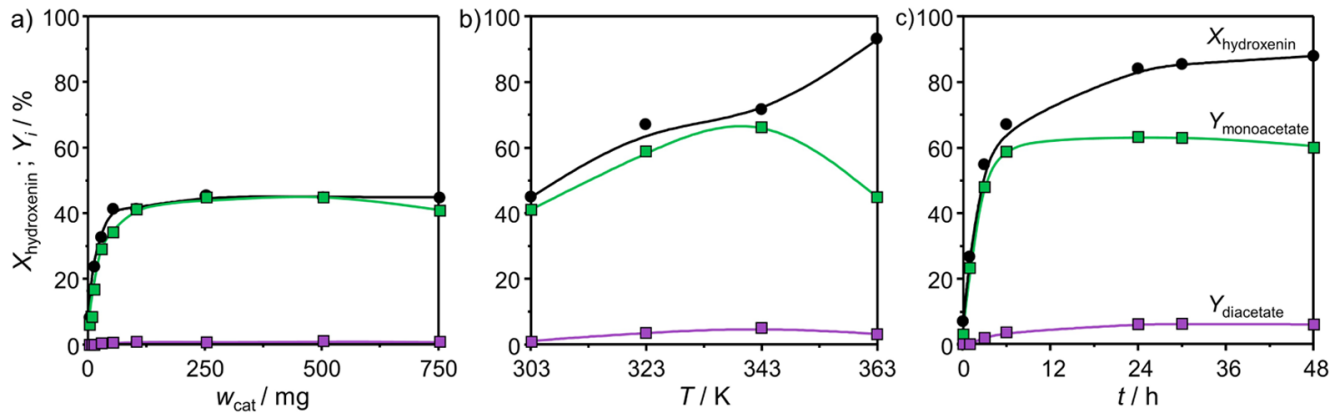

Figure 4. Hydroxenin conversion and product yield over MMO3-973 as a function of the (a) catalyst amount $(T=303 \mathrm{~K}, t=6 \mathrm{~h})$, (b) reaction temperature $\left(t=6 \mathrm{~h}, w_{\text {cat }}=250 \mathrm{mg}\right)$, and $(\mathrm{c})$ reaction time $\left(T=323 \mathrm{~K}, w_{\text {cat }}=250 \mathrm{mg}\right)$. Substrate amount: $n_{\text {hydroxenin }}=3.3 \mathrm{mmol}, n_{\text {acetic anhydride }}=4.3$ $\mathrm{mmol}, V=10 \mathrm{~cm}^{3}$.

existence of intermediate (desorption around $523 \mathrm{~K}$ ) and strong (desorption around $623 \mathrm{~K}$ ) basic sites. ${ }^{46}$ Correlation between the amounts of $\mathrm{CO}_{2}$ desorbed from these two centers (Table S4) and the activity illustrates the balance among the amount and nature of basic sites on the external surface and performance (Figure $3 \mathrm{~b}$ ), and variation of the $\mathrm{Mg} / \mathrm{Al}$ ratio from 1 to 3 has no significant impact. Note that previous studies have reported that thermal activation above $873 \mathrm{~K}$ can diminish the basicity, ${ }^{27}$ but activation at lower temperatures did not lead to an observable benefit in terms of performance.

For comparative purposes, the performance of alkali-metalmodified zeolites, another family of materials commonly applied as base catalysts, was also evaluated. In particular, sodium $(\mathrm{Na}-\mathrm{X})$ - and cesium $(\mathrm{Cs}-\mathrm{X})$-exchanged zeolite $\mathrm{X}$ were prepared by standard methods resulting in materials with typical properties (Table S5). ${ }^{48}$ Although the zeolite catalysts were also selective, neither could match the activity of the assynthesized hydrotalcites (Figure 3a). This likely reflects the fact that the active sites are primarily located within the micropores of the zeolite crystals and the associated accessibility constraints to bulky molecules such as hydroxenin and its acetylated derivatives. Furthermore, the observed yields of hydroxenin monoacetate were significantly lower than the conversions, suggesting a higher extent of substrate or product adsorption in these materials.

2.3. Process Aspects. To improve the efficiency of the hydrotalcite-derived catalysts, effects of the operation parameters on the monoacetylation of hydroxenin and stability aspects were investigated. Varying the catalyst amount from 750 to $100 \mathrm{mg}$ ( $1 \mathrm{~g}$ of substrate) did not significantly impact the performance, while below $100 \mathrm{mg}$, the conversion dropped sharply (Figure 4a). Greater scope for enhancing the monoacetate yield (up to 20\%) was observed upon increasing the reaction temperature from 303 to $323 \mathrm{~K}$ (Figure 4b), while diacetate formation remained minimal $(<2 \%)$. Appreciable deviation between conversion and product yield is evidenced at $363 \mathrm{~K}$, which is related to decomposition of the substrates. The monoacetate yield approaches a maximum value of $63 \%$ between 6 and $24 \mathrm{~h}$ and is not improved by prolonging the reaction time, which promotes slightly increased diacetate formation (Figure 4c). Interestingly, the amount of diacetate formed was substantially lower than that observed in the presence of pyridine at similar levels of hydroxenin conversion, but the selectivity to hydroxenin monoacetate was not improved because of the degradation to other unidentified byproducts.
The best catalyst identified, that is, MMO2-973, was additionally evaluated in five reaction cycles to gather further insights into its stability. The reaction volume was doubled, while maintaining the optimal catalyst amount $\left(25 \mathrm{mg} \mathrm{cm}^{-3}\right)$, in order to recover enough of the spent material for further characterization. In addition, the most promising conditions were selected to conduct this test $(T=323 \mathrm{~K}, t=6 \mathrm{~h})$. The used catalyst was dried overnight at $338 \mathrm{~K}$ between runs. Remarkably, only a minor decrease in the yield of hydroxenin monoacetate was evidenced $(<10 \%)$, while that of hydroxenin diacetate remained below 5\% (Figure 5).

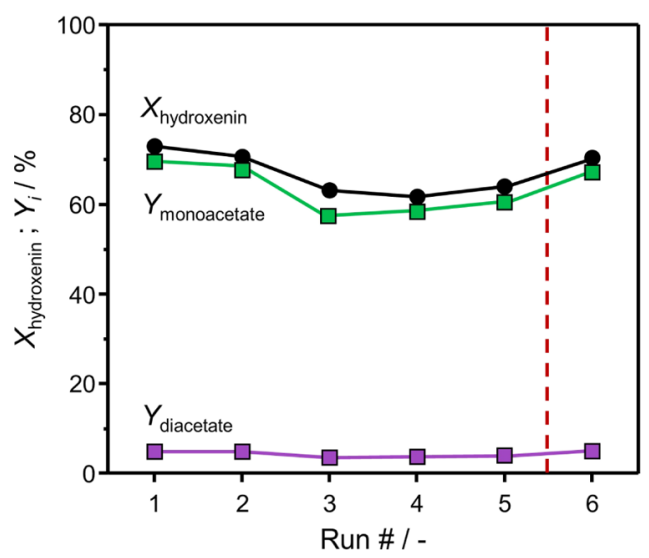

Figure 5. Hydroxenin conversion and product yield in the presence of MMO2-973 over five consecutive reaction cycles and the effect of thermal regeneration (indicated by the red line). Conditions: $T=323$ $\mathrm{K}, t=6 \mathrm{~h}, w_{\text {cat }}=500 \mathrm{mg}, n_{\text {hydroxenin }}=6.6 \mathrm{mmol}, n_{\text {acetic anhydride }}=8.6$ mmol, $V=20 \mathrm{~cm}^{3}$.

Analysis of the catalyst isolated and dried after each run by XRD (Figure 6a) identifies the appearance of sharp new reflections, the intensity of which increases with repeated use, that are most evident in the $10-30^{\circ} 2 \theta$ range, while reflections corresponding to the MMO become less prominent. The multiple new reflections cannot be readily assigned, but the potential crystallization of a hydrotalcite-like compound intercalating the organic component appears unlikely because of the absence of characteristic basal reflections. ${ }^{49,50}$ TGA reveals the gradual accumulation of organic material on the solid, leading to a $48 \%$ weight loss after the first run and increasing up to $78 \%$ after five cycles (Figure $6 \mathrm{~b}$ ). The presence of these compounds is also evidenced by diffuse reflectance infrared Fourier transform spectroscopy (DRIFTS, Figure 6c). Signals in the range of 2935 and $1485 \mathrm{~cm}^{-1}$ can be 

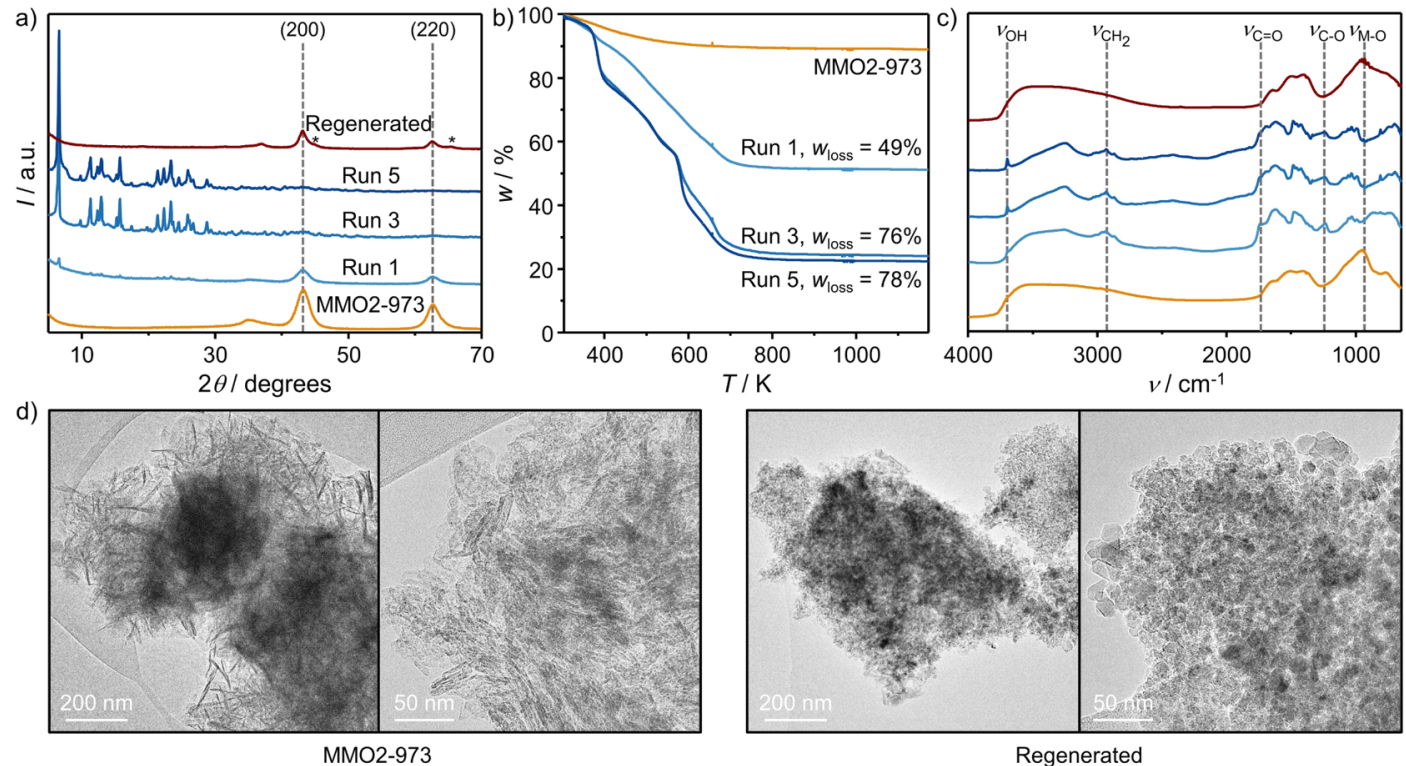

Figure 6. (a) XRD patterns, (b) TGA profiles, and (c) DRIFT spectra of the MMO2-973 catalyst after consecutive catalytic runs compared to the fresh and regenerated material. In (a), asterisks denote additional reflections in the XRD pattern of the regenerated material. Crystallographic open database: $\gamma-\mathrm{Al}_{2} \mathrm{O}_{3}$ (2015530). (d) TEM images of the fresh MMO2-973 catalyst and of the material isolated after use in five catalytic runs and subjected to oxidative regeneration.

assigned to $\mathrm{C}-\mathrm{H}$ and $\mathrm{CH}_{2}$ vibrations, while a peak at 3699 $\mathrm{cm}^{-1}$ indicates some $\mathrm{OH}$ functionality. The presence of both hydroxenin and monoacetate on the used solid is thought likely due to the absorptions observed at $1243 \mathrm{~cm}^{-1}(\mathrm{C}-\mathrm{O})$ and $1640 \mathrm{~cm}^{-1}(\mathrm{C}=\mathrm{C})$.

Oxidative regeneration of the spent material restores the initial mixed metal oxide structure, as confirmed by XRD (Figure 6a). However, minor reflections appear in addition to those of the mixed metal oxide, hinting at some crystallization of a $\gamma-\mathrm{Al}_{2} \mathrm{O}_{3}$ phase. After successful removal of the organic components, the expected aggregated particle structure of the mixed metal oxide can be discriminated by transmission electron microscopy (Figure 6d). ${ }^{37}$ Minor alterations in crystal morphology toward more spherical structures indicate that some restructuring may occur, which could be related to partial reconstruction of the sample during sequential catalytic runs. The morphological change is also reflected by slightly diminished porous properties (Table S6), which is most noticeable from the drop in pore volume (by 60\%), although the reduction in surface area is less significant (12\%). The $\mathrm{Mg}$ / $\mathrm{Al}$ ratio of the used catalyst was in good agreement with the pristine material (Table S6). Furthermore, the fact that the activity could be fully restored upon thermal regeneration highlights the robustness of this reaction in the presence of mixed metal oxides (Figure 5).

\section{CONCLUSIONS}

The application of solid bases as alternatives for pyridine in the synthesis of a key vitamin A intermediate has been demonstrated. Advantageously, hydrotalcites and derived materials comprising earth-abundant and nontoxic elements are found to be highly selective (>90\%) toward monoacetylation of hydroxenin and active under mild conditions ( $T$ $=323 \mathrm{~K})$. The controlled thermal activation of the assynthesized hydrotalcites to form high surface area mixed metal oxides displaying Lewis basic sites was found to lead to significantly enhanced activity. In contrast, a Brønsted basic hydrotalcite, synthesized by reconstruction of a mixed oxide, resulted in a similar performance as the as-synthesized hydrotalcite. Variation of the $\mathrm{Mg} / \mathrm{Al}$ ratio from 1 to 3 has no significant impact. After optimizing the reaction conditions, hydroxenin monoacetate yields of $>55 \%$ can be obtained in five consecutive cycles without the need for any intermediate treatment. The catalyst can be readily recycled and reused, and any deposited organic species can be removed by oxidative regeneration without loss of performance, confirming the potential of hydrotalcite-derived materials as highly selective catalysts for the sustainable production of vitamins.

\section{METHODS}

4.1. Catalyst Preparation. Four $\mathrm{Mg}-\mathrm{Al}-\mathrm{CO}_{3}$ hydrotalcites with nominal $\mathrm{Mg} / \mathrm{Al}$ ratios of $x=1,2,3$, or 4 (coded $\mathrm{HT} x$ ) were synthesized via coprecipitation. A $500 \mathrm{~cm}^{3}$ solution of $0.25-1.0 \mathrm{M} \mathrm{Mg}\left(\mathrm{NO}_{3}\right)_{2} \cdot 6 \mathrm{H}_{2} \mathrm{O}$ (Sigma-Aldrich, $\geq 98 \%$ ) and $0.25 \mathrm{M} \mathrm{Al}\left(\mathrm{NO}_{3}\right)_{3} \cdot 9 \mathrm{H}_{2} \mathrm{O}$ (Sigma-Aldrich, $\geq 98 \%$ ) was slowly added to a magnetically stirred $(500 \mathrm{rpm})$ solution of $600 \mathrm{~cm}^{3}$ of $2 \mathrm{M} \mathrm{Na}_{2} \mathrm{CO}_{3}$ (Sigma-Aldrich, $\geq 99.5 \%$ ) at $298 \mathrm{~K}$. The $\mathrm{pH}$ was kept constant at ca. 10 through the dropwise addition of a 40 wt $\% \mathrm{NaOH}$ solution. The resulting slurry was aged for $6 \mathrm{~h}$ at $333 \mathrm{~K}$ under stirring. Finally, the material was filtered, extensively washed with deionized water to reach a $\mathrm{pH}$ below 7.5 in the filtrate, and dried overnight at $338 \mathrm{~K}$. The absence of residual counterions from the synthesis was confirmed by ensuring that the sodium content in the resulting material was below $1 \mathrm{ppm}$. The corresponding mixed metal oxides were obtained via calcination in static air at $673-1273 \mathrm{~K}$ for $6 \mathrm{~h}$ (5 $\mathrm{K} \mathrm{min}^{-1}$ ) and are labeled as MMO $x-y$, where $x$ indicates the $\mathrm{Mg} / \mathrm{Al}$ ratio and $y$ denotes the activation temperature. Reconstructed r-HT3 was obtained via treatment of MMO3973 in deionized water $\left(100 \mathrm{~cm}^{3}\right.$ per gram of solid) for $6 \mathrm{~h}$ at $298 \mathrm{~K}$ under magnetic stirring $(500 \mathrm{rpm})$. The resulting material was collected by filtration, washed with equivalent amounts of ethanol $\left(100 \mathrm{~cm}^{3}\right.$ per gram of solid), and dried under $\mathrm{N}_{2}$ atmosphere. All solids were stored in a desiccator 
under reduced pressure. For comparative purposes, sodiumand cesium-exchanged zeolite $\mathrm{X}$ were obtained via three consecutive ion exchange treatments of a commercial sample (13X, Acros Organics) with a $0.1 \mathrm{M}$ solution of the corresponding metal nitrate $\left(100 \mathrm{~cm}^{3} \mathrm{~g}_{\text {zeolite }}{ }^{-1}\right)$. The resulting solids were isolated by filtration, washed with deionized water, dried at $338 \mathrm{~K}$ in air, and finally calcined at $823 \mathrm{~K}$ for $6 \mathrm{~h}(5 \mathrm{~K}$ $\left.\min ^{-1}\right)$.

4.2. Catalyst Characterization. Inductively coupled plasma optical emission spectroscopy was performed to determine the metal ratio using a HORIBA Ultima 2 instrument equipped with photomultiplier tube detection. Prior to analysis, samples were dissolved in $10 \mathrm{wt} \% \mathrm{HNO}_{3}$. C, $\mathrm{H}, \mathrm{N}$ analysis was undertaken using a LECO CHN-900 analyzer. Powder XRD patterns were recorded using a PANalytical X'Pert PRO-MPD diffractometer equipped with $\mathrm{Ni}$-filtered $\mathrm{Cu} \mathrm{K} \alpha$ radiation $(\lambda=0.1541 \mathrm{~nm})$. Acquisition took place in the $2 \theta$ range of $5-70^{\circ}$ with an angular step size of $0.05^{\circ}$ and a counting time of $1.4 \mathrm{~s}$ per step. The average crystal size was determined using the Scherrer equation with a shape factor of $K=0.9$. TGA was carried out on Linseis DSC PT1600. Analysis was performed in the temperature range $303-973 \mathrm{~K}$ at a rate of $10 \mathrm{~K} \mathrm{~min}^{-1}$ under $25 \mathrm{~cm}^{3} \mathrm{~min}^{-1} \mathrm{~N}_{2}$ flow. The amount of volatile species in the used solids was determined in air $\left(25 \mathrm{~cm}^{3} \mathrm{~min}^{-1}\right)$ by registering the weight loss curve from 303 to $1173 \mathrm{~K}\left(10 \mathrm{~K} \mathrm{~min}^{-1}\right)$. Nitrogen isotherms were recorded using a Micromeritics TriStar analyzer. Prior to analysis, samples were degassed overnight at $423 \mathrm{~K}$. The total surface area was determined by the Brunauer-Emmett-Teller equation and the pore size was determined by application of the Barrett-Joyner-Halenda method to the adsorption branch of the isotherm. The basicity of the solid catalysts was investigated by the TPD of carbon dioxide $\left(\mathrm{CO}_{2}\right.$-TPD) using a Micromeritics Autochem II chemisorption analyzer. The samples $(0.1 \mathrm{~g})$ were pretreated in a He flow $\left(10 \mathrm{~cm}^{3}\right.$ $\min ^{-1}$ ) at $973 \mathrm{~K}$ for $2 \mathrm{~h}$. Then, $\mathrm{CO}_{2}$ (50 pulses, 0.5 min per pulse, $\left.1 \mathrm{~cm}^{3}\right)$ diluted in $\mathrm{He}\left(10 \mathrm{~cm}^{3} \mathrm{~min}^{-1}\right)$ was dosed at 323 $\mathrm{K}$, followed by removal of excess $\mathrm{CO}_{2}$ in purging $\mathrm{He}$ at the same temperature for $30 \mathrm{~min}$. The desorption curve was recorded by heating from 323 to $973 \mathrm{~K}\left(10 \mathrm{~K} \mathrm{~min}^{-1}\right)$ in flowing $\mathrm{He}\left(10 \mathrm{~cm}^{3} \mathrm{~min}^{-1}\right)$. Desorbed water was trapped using magnesium perchlorate (Sigma-Aldrich, $\geq 98 \%$ ). The concentrations of weak, medium, and strong basic sites were estimated by multiplying the deconvoluted area of the corresponding desorption peak with a calibration factor, which was obtained from the decomposition of known amounts of $\mathrm{CaCO}_{3}$ (Fluka, $\geq 99 \%$ ). Al coordination was investigated using ${ }^{27} \mathrm{Al}$ MAS-NMR on a Bruker AVANCE 400 $\mathrm{MHz}$ spectrometer. Per sample, 512 scans were recorded at a spinning speed of $12.5 \mathrm{kHz}$ with a $4 \mathrm{~mm}$ probe head and $4 \mathrm{~mm}$ $\mathrm{ZrO}_{2}$ rotors. Adsorbed species in the used catalysts were studied by DRIFTS on a Bruker Vertex 400 spectrometer equipped with $\mathrm{N}_{2}$ cooled MCT detector and a Harrick diffuse reflection accessory. Prior to analysis, samples were degassed in $\operatorname{Ar}\left(10 \mathrm{~cm}^{3} \mathrm{~min}^{-1}\right)$ for $1 \mathrm{~h}$ at $298 \mathrm{~K}$ and 64 scans were collected in the $4000-700 \mathrm{~cm}^{-1}$ range with a resolution of 4 $\mathrm{cm}^{-1}$. Transmission electron microscopy (TEM) images were acquired using a FEI Talos F200A instrument operated at 200 $\mathrm{kV}$.

4.3. Catalyst Testing. Acetylation reactions were carried out in a Radleys Carousel 6+ equipped with $100 \mathrm{~cm}^{3}$ twonecked round-bottom flasks and reflux cooling. In a typical experiment, the catalyst (250 $\mathrm{mg}$ unless otherwise indicated), acetic anhydride (0.44 g, $4.3 \mathrm{mmol}$, Merck, $\geq 98.5 \%)$, and substrate $(3.3 \mathrm{mmol}$ of hydroxenin $(\geq 97 \%)$ or hydroxenin monoacetate $(\geq 97 \%))$ in $p$-xylene (Acros, $\geq 99 \%$ ) were reacted in a total volume of $10 \mathrm{~cm}^{3}$ at $T=303-363 \mathrm{~K}$ at ambient pressure under time-resolved sampling. Comparative studies were carried out in the absence of catalyst or in the presence of pyridine $(2.6 \mathrm{mmol})$. Catalyst recyclability was investigated over five consecutive reactions followed by regeneration at $973 \mathrm{~K}$. To ensure a constant total amount, the catalyst was carefully recovered after each catalytic run by centrifugation. Samples were analyzed using an Agilent 1260 Infinity HPLC equipped with an Agilent Zorbax Plus C18 column and a diode array detector $(235 \mathrm{~nm})$ and a wateracetonitrile gradient $\left(0.5 \mathrm{~cm}^{3} \mathrm{~min}^{-1}\right)$ at $313 \mathrm{~K}$ (Table S7). The conversion of substrate $i\left(X_{i}\right)$ was calculated as the number of moles of the substrate reacted divided by the initial number of moles of the substrate. The yield $\left(Y_{i}\right)$ or selectivity $\left(S_{i}\right)$ of product $i$ was denoted as the number of moles of product formed divided by either the initial amount of substrate or the total number of moles of products, according to the following equations:

$$
\begin{aligned}
& X_{\text {substrate } i}=1-n_{\text {substrate } i}(t) / n_{\text {substrate } i}(t=0) \\
& Y_{\text {product } i}=n_{\text {product } i}(t) / n_{\text {substrate } i}(t=0) \\
& S_{\text {product } i}=n_{\text {product } i}(t) / \sum n_{\text {products }}(t=0)
\end{aligned}
$$

${ }^{1} \mathrm{H}(300 \mathrm{MHz})$ and ${ }^{13} \mathrm{C} \mathrm{NMR}(75 \mathrm{MHz})$ spectra of the reagents and products (Data S1, Figures S10-S15) were recorded on a Bruker AVANCE III instrument and are reported relative to residual solvent: $\mathrm{CHCl}_{3}, \delta=7.26\left({ }^{1} \mathrm{H}\right)$ or $77.16\left({ }^{13} \mathrm{C}\right) \mathrm{ppm}$. Data for ${ }^{1} \mathrm{H}$ NMR are reported as follows: chemical shift $(\delta / \mathrm{ppm})$, multiplicity (br-broad, s-singlet, $\mathrm{d}$-doublet, $\mathrm{t}$-triplet, $\mathrm{q}$-quartet, $\mathrm{m}$ - multiplet, $\mathrm{dd}$-doublet of doublets, and $\mathrm{dt}-$ doublet of triplets), coupling constant $(\mathrm{Hz})$, and integration.

\section{ASSOCIATED CONTENT}

\section{Supporting Information}

The Supporting Information is available free of charge on the ACS Publications website at DOI: 10.1021/acsomega.8b02234.

Additional characterization and catalytic data (PDF)

\section{AUTHOR INFORMATION}

\section{Corresponding Authors}

*E-mail: msharon@chem.ethz.ch (S.M.).

*E-mail: jpr@chem.ethz.ch (J.P.-R.).

ORCID

Javier Pérez-Ramírez: 0000-0002-5805-7355

\section{Notes}

The authors declare no competing financial interest.

\section{ACKNOWLEDGMENTS}

The authors acknowledge the microscopy center (ScopeM) of ETH Zurich for access to its facilities. Dr. R. Verel (ETH Zurich) and E. Vorobyeva (ETH Zurich) are thanked for assistance with the NMR and TEM analyses, respectively. 


\section{REFERENCES}

(1) Eggersdorfer, M.; Laudert, D.; Létinois, U.; McClymont, T.; Medlock, J.; Netscher, T.; Bonrath, W. One Hundred Years of Vitamins-A Success Story of the Natural Sciences. Angew. Chem., Int. Ed. 2012, 51, 12960-12990.

(2) Kontis, V.; Bennett, J. E.; Mathers, C. D.; Li, G.; Foreman, K.; Ezzati, M. Future Life Expectancy in 35 Industrialized Countries: Projections with a Bayesian Model Ensemble. J. Lancet 2017, 389, 1323-1335.

(3) Bonrath, W.; Netscher, T. Catalytic Processes in Vitamins Synthesis and Production. Appl. Catal., A 2005, 280, 55-73.

(4) Filipponi, P.; Gioiello, A.; Baxendale, I. R. Controlled Flow Precipitation as a Valuable Tool for Synthesis. Org. Process Res. Dev. 2016, 20, 371-375.

(5) Delidovich, I.; Palkovits, R. Catalytic Versus Stoichiometric Reagents as a Key Concept for Green Chemistry. Green Chem. 2016, $18,590-593$.

(6) Ciriminna, R.; Pagliaro, M. Green Chemistry in the Fine Chemicals and Pharmaceutical Industries. Org. Process Res. Dev. 2013, 17, 1479-1484.

(7) Bonrath, W. New Trends in (Heterogeneous) Catalysis for the Fine Chemicals Industry. Chimia 2014, 68, 485-491.

(8) Zaera, F. New Challenges in Heterogeneous Catalysis for the $21^{\text {st }}$ Century. Catal. Lett. 2012, 142, 501-516.

(9) Harrison, C. Patenting Natural Products just Got Harder. Nat. Biotechnol. 2014, 32, 403-404.

(10) Parker, G. L.; Smith, L. K.; Baxendale, I. R. Development of the Industrial Synthesis of Vitamin A. Tetrahedron 2016, 72, 1645-1652.

(11) Orsat, B.; Wirz, B.; Bischof, S. A Continuous Lipase-Catalyzed Acylation Process for the Large-Scale Production of Vitamin A Precursors. Chimia 1999, 53, 579-584.

(12) Bonrath, W.; Karge, R.; Netscher, T. Lipase-Catalyzed Transformations as Key-Steps in the Large-Scale Preparation of Vitamins. J. Mol. Catal. B: Enzym. 2002, 19-20, 67-72.

(13) Isler, O.; Huber, W.; Ronco, A.; Kofler, M. Synthese des Vitamin A. Helv. Chim. Acta 1947, 30, 1911-1927.

(14) Isler, O. Process for the Manufacture of Pentaenes. U.S. Patent 2451739A, 1948.

(15) Sels, B. F.; De Vos, D. E.; Jacobs, P. A. Hydrotalcite-Like Anionic Clays in Catalytic Organic Reactions. Catal. Rev. 2001, 43, 443-488.

(16) Wang, Q.; O'Hare, D. Recent Advances in the Synthesis and Application of Layered Double Hydroxide (LDH) Nanosheets. Chem. Rev. 2012, 112, 4124-4155.

(17) Li, C.; Wei, M.; Evans, D. G.; Duan, X. Layered Double Hydroxide-based Nanomaterials as Highly Efficient Catalysts and Adsorbents. Small 2014, 10, 4469-4486.

(18) Baskaran, T.; Christopher, J.; Sakthivel, A. Progress on Layered Hydrotalcite (HT) Materials as Potential Support and Catalytic Materials. RSC Adv. 2015, 5, 98853-98875.

(19) Choudary, B. M.; Kantam, M. L.; Reddy, C. R. V.; Rao, K. K.; Figueras, F. The First Example of Michael Addition Catalysed by Modified Mg-Al Hydrotalcite. J. Mol. Catal. A: Chem. 1999, 146, 279-284.

(20) Tichit, D.; Lutic, D.; Coq, B.; Durand, R.; Teissier, R. The Aldol Condensation of Acetaldehyde and Heptanal on HydrotalciteType Catalysts. J. Catal. 2003, 219, 167-175.

(21) Cueto, J.; Faba, L.; Díaz, E.; Ordóñez, S. Performance of Basic Mixed Oxides for Aqueous-Phase 5-Hydroxymethylfurfural-Acetone Aldol Condensation. Appl. Catal., B 2017, 201, 221-231.

(22) Corma, A.; Hamid, A.; Iborra, S.; Velty, A. Lewis and Brönsted Basic Active Sites on Solid Catalysts and their Role in the Synthesis of Monoglycerides. J. Catal. 2005, 234, 340-347.

(23) Xie, W.; Peng, H.; Chen, L. Calcined Mg-Al Hydrotalcites as Solid Base Catalysts for Methanolysis of Soybean Oil. J. Mol. Catal. A 2006, 246, 24-32.

(24) Di Serio, M.; Ledda, M.; Cozzolino, M.; Minutillo, G.; Tesser, R.; Santacesaria, E. Transesterification of Soybean Oil to Biodiesel by using Heterogeneous Basic Catalysts. Ind. Eng. Chem. Res. 2006, 45, 3009-3014.

(25) Liu, Y.; Lotero, E.; Goodwin, J. G.; Mo, X. Transesterification of Poultry Fat with Methanol using $\mathrm{Mg}-\mathrm{Al}$ Hydrotalcite Derived Catalysts. Appl. Catal., A 2007, 331, 138-148.

(26) Álvarez, M. G.; Chimentão, R. J.; Figueras, F.; Medina, F. Tunable Basic and Textural Properties of Hydrotalcite Derived Materials for Transesterification of Glycerol. Appl. Clay Sci. 2012, 58, $16-24$.

(27) Liu, P.; Derchi, M.; Hensen, E. J. M. Synthesis of Glycerol Carbonate by Transesterification of Glycerol with Dimethyl Carbonate over MgAl Mixed Oxide Catalysts. Appl. Catal., A 2013, 467, 124-131.

(28) Hájek, M.; Kutálek, P.; Smoláková, L.; Troppová, I.; Čapek, L.; Kubička, D.; Kocík, J.; Thanh, D. N. Transesterification of Rapeseed Oil by $\mathrm{Mg}-\mathrm{Al}$ Mixed Oxides with Various $\mathrm{Mg} / \mathrm{Al}$ Molar Ratio. Chem. Eng. J. 2015, 263, 160-167.

(29) Deryabina, E. L.; Vasil'eva, R. L.; Deineka, B. I. Studies in the Synthesis of Retinoids II. Acetylation of C20 Diolyne and C20 Diol. Pharm. Chem. J. 1992, 26, 456-458.

(30) Staroverov, V. M.; Deineka, V. I.; Vysochin, A. P.; Vasil'eva, R. L.; Deryabina, E. L.; Rudakova, N. M. Investigations in the Field of Retinoid Synthesis 1. Chromatographic Behavior of Diolyne C20, DIOL C20, and their Acetylation Products. Pharm. Chem. J. 1992, 26, 406-410.

(31) Schmidt, C.; Pragst, F. Voltammetrische Untersuchung des Acylierungsgleichgewichtes von Pyridin in Acetanhydrid. Z. Chem. 2010, 24, 332-333.

(32) Fan, G.; Li, F.; Evans, D. G.; Duan, X. Catalytic Applications of Layered Double Hydroxides: Recent Advances and Perspectives. Chem. Soc. Rev. 2014, 43, 7040-7066.

(33) Delidovich, I.; Palkovits, R. Structure-Performance Correlations of $\mathrm{Mg}-\mathrm{Al} \mathrm{Hydrotalcite}$ Catalysts for the Isomerization of Glucose into Fructose. J. Catal. 2015, 327, 1-9.

(34) Debecker, D. P.; Gaigneaux, E. M.; Busca, G. Exploring, Tuning, and Exploiting the Basicity of Hydrotalcites for Applications in Heterogeneous Catalysis. Chem.-Eur. J. 2009, 15, 3920-3935.

(35) Lari, G. M.; de Moura, A. B. L.; Weimann, L.; Mitchell, W. S.; Mondelli, C.; Pérez-Ramírez, J. Design of a Technical Mg-Al Mixed Oxide Catalyst for the Continuous Manufacture of Glycerol Carbonate. J. Mater. Chem. A 2017, 5, 16200-16211.

(36) Abelló, S.; Medina, F.; Tichit, D.; Pérez-Ramírez, J.; Rodríguez, X.; Sueiras, J. E.; Salagre, P.; Cesteros, Y. Study of Alkaline-Doping Agents on the Performance of Reconstructed $\mathrm{Mg}-\mathrm{Al}$ Hydrotalcites in Aldol Condensations. Applied Catalysis, A 2005, 281, 191-198.

(37) Warringham, R.; Mitchell, S.; Murty, R.; Schäublin, R.; Crivelli, P.; Kenvin, J.; Pérez-Ramírez, J. Mapping the Birth and Evolution of Pores upon Thermal Activation of Layered Hydroxides. Chem. Mater. 2017, 29, 4052-4062.

(38) Fripiat, J. J. High Resolution Solid State NMR Study of Pillared. Catal. Today 1988, 2, 281-295.

(39) Aramendía, M. A.; Avilés, Y.; Borau, V.; Luque, J. M.; Marinas, J. M.; Ruiz, J. R.; Urbano, F. J. Thermal Decomposition of $\mathrm{Mg} / \mathrm{Al}$ and $\mathrm{Mg} / \mathrm{Ga}$ Layered-Double Hydroxides: A Spectroscopic Study. J. Mater. Chem. 1999, 9, 1603-1607.

(40) Winter, F.; Xia, X.; Hereijgers, B. P. C.; Bitter, J. H.; van Dillen, A. J.; Muhler, M.; de Jong, K. P. On the Nature and Accessibility of the Brønsted-Base Sites in Activated Hydrotalcite Catalysts. J. Phys. Chem. B 2006, 110, 9211-9218.

(41) Mitchell, S.; Biswick, T.; Jones, W.; Williams, G.; O’Hare, D. A Synchrotron Radiation Study of the Hydrothermal Synthesis of Layered Double Hydroxides from $\mathrm{MgO}$ and $\mathrm{Al}_{2} \mathrm{O}_{3}$ Slurries. Green Chem. 2007, 9, 373-378.

(42) Tichit, D.; Gérardin, C.; Durand, R.; Coq, B. Layered Double Hydroxides: Precursors for Multifunctional Catalysts. Top. Catal. 2006, 39, 89-96.

(43) Cantrell, D. G.; Gillie, L. J.; Lee, A. F.; Wilson, K. StructureReactivity Correlations in MgAl Hydrotalcite Catalysts for Biodiesel Synthesis. Appl. Catal., A 2005, 287, 183-190. 
(44) Takehira, K. Recent Development of Layered Double Hydroxide-Derived Catalysts - Rehydration, Reconstitution, and Supporting, Aiming at Commercial Application. Appl. Clay Sci. 2017, 136, 112-141.

(45) Abelló, S.; Medina, F.; Tichit, D.; Pérez-Ramírez, J.; Groen, J. C.; Sueiras, J. E.; Salagre, P.; Cesteros, Y. Aldol Condensations over Reconstructed $\mathrm{Mg}-\mathrm{Al}$ Hydrotalcites: Structure-Activity Relationships related to the Rehydration Method. Chem.-Eur. J. 2005, 11, 728-739.

(46) Di Cosimo, J. I.; Díez, V. K.; Xu, M.; Iglesia, E.; Apesteguía, C. R. Structure and Surface and Catalytic Properties of Mg-Al Basic Oxides. J. Catal. 1998, 178, 499-510.

(47) Millange, F.; Walton, R. I.; O’Hare, D. Time-Resolved in situ Xray Diffraction Study of the Liquid-Phase Reconstruction of $\mathrm{Mg}-\mathrm{Al}-$ Carbonate Hydrotalcite-Like Compounds. J. Mater. Chem. 2000, 10, $1713-1720$.

(48) Martín, A. J.; Mitchell, S.; Scholder, O.; Verel, R.; Hauert, R.; Bernard, L.; Jensen, C.; Schwefer, M.; Pérez-Ramírez, J. Elucidating the Distribution and Speciation of Boron and Cesium in BCsX Zeolite Catalysts for Styrene Production. ChemPhysChem 2018, 19, 437-445.

(49) Hwang, S. H.; Han, Y. S.; Choe, J. H. Intercalation of Functional Organic Molecules with Pharmaceutical, Cosmeceutical and Nutraceutical Functions into Layered Double Hydroxides and Zinc Basic Salts. Bull. Korean Chem. Soc. 2001, 22, 1019-1022.

(50) Choy, J.-H.; Son, Y.-H. Intercalation of Vitamer into LDH and their Controlled Release Properties. Bull. Korean Chem. Soc. 2004, 25, $122-126$. 